\title{
Urgences
}

\section{Théorie des tables (extraits)}

Emmanuel Hocquard

Numéro 33, octobre 1991

Poésies parallèles : France - Québec

URI : https://id.erudit.org/iderudit/025665ar

DOI : https://doi.org/10.7202/025665ar

Aller au sommaire du numéro

Éditeur(s)

Urgences

ISSN

0226-9554 (imprimé)

1927-3924 (numérique)

Découvrir la revue

Citer ce document

Hocquard, E. (1991). Théorie des tables (extraits). Urgences, (33).

https://doi.org/10.7202/025665ar d'utilisation que vous pouvez consulter en ligne.

https://apropos.erudit.org/fr/usagers/politique-dutilisation/ 
Emmanuel Hocquard

Normand de Bellefeuille 


\section{Théorie des tables (extraits)}

\section{Emmanuel Hocquard}

\section{7}

Hier est en face

Chère Maya, ton nuage

au-dessus de

quelqu'un se rendort

Une valise est verte

a contenu sa clef

Le verre se brille

Puissance \& Chaleur

dans la technique du sommeil 
48

Chère E., tu dis non je ne sais pas

Est-ce que tu t'en vas?

tu ne restes pas

À quelle distance une vague est bleue?

Une question ne répond pas répond 
54

49

Le nom du jour est: indigo

De quoi as-tu peur?

veut dire nous

deux ou je

Quelle est la longueur d'un livre?

Cher Jule, chère Juliette

un nom contient un autre nom

Écout' l'âne, cout' la chèvre 
Cinquante $=$ trois $=$ dix

signifie pas un

Pas un ne reste

Une palme violette veut dire penser une nuit de plus

Penser veut dire quelque chose est encore de trop 
56

51

A Emmanuel

Regarde, c'est moi

à trois ans

Les mains dans les poches

mars 1950

Deux pronoms sur ma table or on dit toujours autre chose

Eh Kid! Regarde-moi ce front et ces yeux, ce sourire!

Oui 